\title{
Effects of Visible Light Wavelengths on Seed Germinability in Stevia Rebaudiana Bertoni
}

\author{
Raji Akintunde Abdullateef (Corresponding author) \\ Kulliyyah of Science, International Islamic University Malaysia (IIUM) \\ 25200 Kuantan, Pahang, Malaysia \\ Tel: 60-129-141-037 E-mail: abdullateef raji@yahoo.com \\ Mohamad Osman \\ Kulliyyah of Science, International Islamic University Malaysia (IIUM) \\ 25200 Kuantan, Pahang, Malaysia \\ Tel: 60-957-16-759 E-mail: mbopar2004@yahoo.com
}

Received: July 7, 2011 Accepted: July 25, 2011 doi:10.5539/ijb.v3n4p83

This research was financed by International Islamic University Malaysia (IIUM) under Endowment EDW B 10-116-0455(Sponsoring information).

\begin{abstract}
Stevia rebaudiana Bertoni is one of 154 members of the genus Stevia and it produces sweet steviol glycosides .It originated from Paraguay. The leaves were used as general sweetening agent. Seed germination in Stevia is generally very low and constituted major obstacle to large scale production of the crop. Different wavelengths from visible light were tested on germination of Stevia seeds. The two lights used were (i) white light - 400 to 700nm, and (ii) red light - 660nm. Parameters evaluated include (i) Mean time germination, (ii) mean daily germination, (iii) germination rate, (iv) daily germination speed and (v) germination value. Multivariate tests at probability level $<.05$ revealed that daily germination speed and number of germinated seeds were significantly higher at $(<.001)$ and $(<.014)$ respectively with the effect of red light on seed germination. Red light $(660 \mathrm{~nm})$ had better influence on germination in Stevia seeds than white light (400-700nm) and control experiment.
\end{abstract}

Keywords: Stevia, steviol glycosides, Seed germination, Visible light wavelengths, Malaysia

\section{Introduction}

Stevia rebaudiana Bert. is a member of the genus Stevia and one of only two that produce sweet steviol glycosides (Soejarto et al., 1982, 1983). It is native to subtropical and tropical South America and Central America (Robert, 2010). Stevia was first brought to the attention of Europeans in 1887 when M.S. Bertoni learned of its unique properties from the Paraguayan Indians and Mestizos (Lewis, 1992). Various reports cited by Lewis (1992) indicated that it was long known to the Guarani Indians of the Paraguayan highlands who called it sweet herb. The leaves were used either to sweeten tea or as a general sweetening agent.

Since the 1970s, Stevia extracts have been widely used in many countries as a sugar substitute. It was reported that in Japan Stevia extracts account for about 5.6\% of the sweetener market (Strauss 1995). It is considered as a good substitute of sugar. Diabetic patients can take herbal powder of Stevia available in market as it lowers down the sugar level, giving the sweet taste of sugar. It is a non-caloric sweetener, the sweet compounds pass through the digestive process of the body without chemically breaking down, thus making Stevia a safe substance for consumption for people who need to reduce the sugar content of their Blood (Strauss, 1995).From most of the previous work, Stevia has been reported to have no adverse effect on humans (Brandle and Rosa, 1992). The leaves could be eaten fresh or when dried and it could be boiled in tea to release the sweetener. It has been used for centuries by the Guarani Indians of Paraguay, where the plant originated from, as sweeteners for mate tea (Goettemoeller and Ching, 1999). 
Propagation in this crop is usually through stem cuttings and not by seeds; this is simply because growing Stevia from seeds normally has a very low germination success; sometimes only 10\%.( Sakaguchi and Kan, 1982). The poor seed germination problem in this crop posed a lot of obstacles towards large scale establishment of the crop and thereby making the available plant materials costly. With the rise in percentage of diabetic human population across the World, Malaysians inclusive, the dare need to seek for a brake through that would allow Stevia propagation by seed becomes inevitable. (Goettemoeller and Ching, 1999).

Light is known to play important roles in plant development as it is a necessary condition for photosynthesis to occur. Organic products of photosynthesis are utilized to feed the plants, assist in cellular activities and also to support the plant's structure.

Effects of light, as an important factor that can influence seed germination and seedling growth of some plants have been earlier reported by researchers. Light could influence some seeds to germinate, while in some seeds presence of light could also cause inhibition. Anchalee (2011) stated in the report of his findings that different light treatments could lead to various effects on different seed germination parameter of Nepenthes mirabilis.

Different types of visible light such as white (400-700), green $(510 \mathrm{~nm})$, yellow $(570 \mathrm{~nm})$, red $(660 \mathrm{~nm})$ and blue $(475 \mathrm{~nm})$ have been used to stimulate germination in seeds, previous work carried out in this aspect with seed germination experiment on Nepenthes mirabilis (Anchalee, 2011) showed that though white and red light influenced germination in seeds, the effect due to red light was unparalleled.

The aim of this research therefore is to study the effects of some visible light wavelengths on seed germinability Stevia rebaudiana.

\section{Materials and method}

Wavelengths from visible spectrum were utilized to germinate Stevia seeds in this experiment. The two lights used were (i) white light, a mixture of the colours of the visible spectrum with wavelengths ranging from 400 to $700 \mathrm{~nm}$, and (ii) red light with a wavelength $660 \mathrm{~nm}$.

The experimental set up was such that a metal construction was designed in the kulliyyah of science, International Islamic University, Malaysia. The construct was of two chambers namely chamber A and chamber B. Chamber A comprised of two full lengths of white fluorescent tube, while chamber B comprised of two full lengths of red fluorescent tubes.

The construct was made to rest on a laboratory bench. The fluorescent tubes were fixed at the roofs of the metal construct and then connected to source of electricity for power supply.

Randomized complete block design was employed in the experimental design. 200 black seeds of Stevia were collected for the light treatment. Two large pieces of white paper towels were utilized, each was cut into four pieces and 25 seeds of Stevia were transferred into fold of each towel. The paper towels were slightly wet with water to keep them moist and four pieces were transferred into each of the two light chambers A and B. In each chamber therefore there were four replicates of 25 seeds making up hundred per chamber.

In order to keep the paper towels in moist state in order to avert quick desiccation each was inserted in flat colourless plastic. Distance between the seeds on chamber platform and the florescent tube (source of light) was kept at $16.3 \mathrm{~cm}$. After the experiments were set up, the light was switched on at the same time in each chamber and the room temperature was set at $24^{\circ} \mathrm{C}$, while the experiments were on (Goettemoeller and Ching, 1999).

Similarly as a control experimental set up (without light) hundred seeds were also collected and made into four replicates, seeds were sown in peat moss in planting trays on the same day and also kept under same temperature as above.

Seeds were observed for germination in all set ups every other day for a period of two and half weeks. Seeds were considered to have germinated if the cotyledons or radicles appeared from the seed coat (Datta et al, 2009).

Germinated seeds during observation were transferred into different planting trays and kept under moist condition for about five days before finally being transplanted into polythene bags on the field.

The parameters evaluated in this work include (i) mean time germination (MTG) $=\sum$ (nidi) / $\sum$ ni, where di= days taken after sowing, ni=number of germinated seeds in di, and $\sum$ ni $=$ total number of germinated seeds during seven days.; (ii) mean daily germination (MDG) =Final germination percentage / number of days to final germination (Rubio-Casal et al., 2003) cited by (Datta et al, 2009) in Journal of Applied Sciences \& Environmental Management; (iii) germination rate $(\mathrm{GR})=(\mathrm{n} 1 \mathrm{t} 1)+(\mathrm{n} 2 \mathrm{t} 2)+\ldots+(\mathrm{nxtx}) / \mathrm{Xn}$ where $\mathrm{n} 1$ is the number of germinant at the first day of germination, $\mathrm{t} 1$ is the days from start to first germination, and $\mathrm{Xn}$ is the total number of seeds germinated (Rubio-Casal et al.,2003) also cited by (Datta et al, 2009) in same journal as 
above; (iv) daily germination speed (DGS) (Forestry Department, 2011) = cumulative percentage germination / the number of days since sowing $(\mathrm{v})$ germination value $\left.(\mathrm{GV})=\left(\sum \mathrm{DGS} / \mathrm{N}\right) \mathrm{XGP} / 10\right)$ (Forestry Department, 2011), where $\mathrm{DGS}=$ daily germination speed= number of daily counts of germinated seeds from the date of first germination, and $\mathrm{GP}=$ germination percentage at the end of whole experiment, and (vi) final germination percentage $(\mathrm{FGP})=$ number of germinated seeds/total number of sown seeds $\mathrm{x} 100 \%$.

Data collected from experiment were subjected to statistical analysis using multivariate tests at probability level $<.05$. Histograms and line graphs were also plotted in order to statistically support the data collected (figures 1a and $b$ ) and pictures of some of the experimental set ups were also taken (figures $2 a$ to $5 b$ ).

\section{Results and discussions}

The obtained results are presented in tables 1 and 2. While table 1showed the effects of red \& white lights on period of germination and number of germinated seeds along with the control set up, table 2 showed data on evaluated seed germination parameters.

Statistical analysis using the multivariate tests at probability level $<.05$ revealed that daily germination speed (DGS) was significantly higher $(<.001)$ with effect of red light on seed germination than with the effect of white light and control set up. The number of germinated seeds was also significantly high $(<.014)$ with the red light effect over the white light and the control experiment.

Histograms and line graphs illustrate the pictorial view of the analyzed data as shown in the figures $1 \mathrm{a}$ and $\mathrm{b}$, while plates representing pictures of the seeds, chamber settings and growing Stevia plants were placed in figures $2 \mathrm{a}$ to $5 \mathrm{~b}$.

From the obtained results (table1) Stevia seeds treated with wavelength $660 \mathrm{~nm}$ (red light) germinated earlier than the seeds treated with wavelength range $400-700 \mathrm{~nm}$ (white light) and the control experiment. On the $3^{\text {rd }}$ to $4^{\text {th }}$ day of observation only seeds with red light treatment had three germinated seeds, while there was none with seeds treated with white light and control experiment. The germination rate (GR) was 5.00 with red light influence as against 6.45 with white light, and 12.00 without light, Seeds, just as in vegetative parts of plants, could have varying responses to different light in respect of germination, David and Chawan (1970), and Shyam and David (1975) earlier reported that the region of red light spectrum $(590$ and $680 \mu \mathrm{m})$ was most effective in influencing germination in seeds.

Between the $5^{\text {th }}$ and $6^{\text {th }}$ day again there were 17 germinated seeds with red light treatment, while only two seeds germinated under the white light treatment and non for the control, meaning therefore that between the first six days of different wavelength treatments, the red light influenced $20 \%$ seed germination, as compared to $2 \%$ seed germination with white light and $0 \%$ for the control. The efficacy observed in red light over white light in respect of percentage germination was similarly reported in past research work where red light was used to promote germination in seeds of Asteracantha longifolia (David and Chawan, 1970) and Cucumis callosus (Bansal and David, 1978).

However seeds under white light treatment produced 25 germinated seeds between the $7^{\text {th }}$ and the $8^{\text {th }}$ day of treatment, while between same days, the red light treated seeds had seven germinated seeds and no seed germination was recorded under the control experiment still. On the $9^{\text {th }}$ and the $10^{\text {th }}$ day no seed was recorded to germinate with either of the two treatments along with the control set up, but another 12 seeds germinated between $11^{\text {th }}$ and $13^{\text {th }}$ day among seeds treated with red light, there was no germination between these days with white light treated seeds while 10 seeds were recorded to germinate under the control set up. Between the $17^{\text {th }}$ and the $19^{\text {th }}$ day, two seeds germinated with red light treatment while four seeds each germinated with white light treatment and control experiment. Final percentage germination (FGP) after 19 days of observation on Stevia seeds revealed that the red light with wavelength $660 \mathrm{~nm}$ had the highest percentage on Stevia seed germination $(41 \%)$ as against the white light with wavelength range $400-700 \mathrm{~nm}(31 \%)$ and the control experiment $(14 \%)$. The statistical analysis using the multivariate tests at probability level $<.05$ also showed that number of germinated seeds was significantly higher $(<.014)$ with the red light effect over the white light and the control experiment, the result supported findings made by Steel and Torrie (2010) where they recorded highest percentage germination of some Merremia sp. with red light treatment. The observed delay (almost two weeks) and low seed germination in the control experiment as compared to the performances in light treated seeds give an insight that Stevia seeds may be in the category of light-requiring seeds, where seeds could better or only germinate if exposed to light, Goettemoeller and Ching (1999) earlier reported that light has influence on germination in Stevia seeds. It had also been reported earlier that all light-requiring seeds exhibit dormancy, (Lincoln and Eduardo, 2010) and further, Anchalee, (2011) reported light is an important factor responsible for both seed germination and seedling growth. 
Light generally is a necessary condition for plants to photosynthesize and produce food in form of carbohydrate which is utilized for plant's growth and structural development. The knowledge about the effect on light on plant's development therefore is not new, rather little is known about the effect of light on seed germinabilty.

In the recent times some research studies are being carried out on types of light, intensities of light and their different effects on seed germination. Some of the results of previous works revealed that different wavelength of lights can actually influence seed germination either positively or negatively.

In this present work, the research was actually carried out in order find a better approach to germination in Stevia seeds. Stevia is often not being propagated by seeds because of poor level of germination over the years; rather stem cutting had been selected as a means of propagation in the crop. The obtained result in this experiment for the control set up which showed $14 \%$ germination is a clear vindication of previous work on poor Stevia seed germination. Sakaguchi and Kan, (1982) earlier reported that growing Stevia from seed normally has a very low germination success; sometimes only $10 \%$.

However, the treatments of these seeds with red $(660 \mathrm{~nm})$ and white $(400-700 \mathrm{~nm})$ lights showed improvement on the seed germination character of the plant. Considering the studied parameters on seed germination employed in this work the two lights had better influence on Stevia seed germination than without light condition (the control experiment), while the influence of the red light was higher still than the white light on Stevia seed germination.

From the results obtained, the mean time germination (MTG), which was calculated during a period of seven days, showed that the red light treatment had 5.13 while the white light had 6.88 values. This indicated that the red light influenced seeds of Stevia germinated faster in lesser time than in the seeds with white light influence. Since there was no germination recorded for the control experiment within this period the mean time germination was zero. Furthermore when the mean daily germination (MDG) was calculated the red light had 2.28 values as against 1.72 values recorded for white light and 0.83 recorded for the control experiment. This yet proved that more seeds germinated on daily basis with red light influence than with the white light and thus the control. Statistical analysis using the multivariate tests at probability level $<.05$ revealed that daily germination speed (DGS) was significantly higher $(<.001)$ with effect of red light on seed germination than with the effect of white light and control set up. With the germination values (GV) (Combination of both germination speed and total germination [Hossain et al, 2005] ) also, seeds influenced with red light irradiation had the highest values (1.87) than seeds with white light (1.33) and seeds without light (0.15) influences. These results conform to previous findings that seed germinations are influenced differently under different light (Colbach, 2002), and that red light spectrum (590 and $680 \mathrm{~nm}$ ) was most effective in influencing seed germination David and Chawan (1970), and Shyam and David (1975).

Histograms with superimposed line graphs in figures $1 \mathrm{a}$ and $\mathrm{b}$ are expressions on period of germination in respect of number of germinated seeds with red and white lights treatment respectively. Figure 1a revealed an evenly distributed curve in period of germination with red light treatment meaning therefore that (i) seeds germinated between 3.0 to 12.5 and above days; (ii) there were seed germination from day 3 to day 8.5 , between day 9 and day 10.5 there was no seed germination, and last seed germination occurred from day 11 to 12.5 and above, and (iii) number of germinated seeds increases steadily from day 3(3seeds) and attained peak from day 6 to day 7.5 ( 24 seeds) before it started to decline from day 8.5 ( 0.0 seed) to day 11 . However more seeds germinated from day 11.5 to day 12.5 (12 seeds) and above.

Figure $1 \mathrm{~b}$ showed that the graph skewed to the left, this an indication that - (i) there was an irregularity in seed germination across the period of observation (ii) number of germinated seeds was at peak between day7.5 to day 8.5 ( 25 seeds), and (iii) day 0.0 to 5.0 and day 15 to 20 witnessed low seed germination with two and four seeds respectively, while there was no seed germination between the $11^{\text {th }}$ and $14^{\text {th }}$ day.

\section{Conclusion}

Light has influence on seed germination. The germination potential in Stevia seeds was enhanced with the effects of both red and white lights much more than the control (without light) experiment. Red light $(660 \mathrm{~nm})$ had better influence on germination in Stevia seeds than white light $(400-700 \mathrm{~nm})$. Stevia seeds require light for germination.

\section{Acknowledgement}

We are thankful to the research management center of the International Islamic University Malaysia (IIUM) for sponsoring this research through the endowment fund, 'EDW B 10-116-0455' JAZAKUMULLAHU KHAIRAH. 


\section{References}

Anchalee Jala. (2011). Effects of Different Light Treatments on the Germination of Nepenthes mirabilis International Transaction Journal of Engineering, Management, \& Applied Sciences \& Technologies. Volume 2 No.1 eISSN: 1906- 9642. [Online] Available: http://TuEngr.com/V02/083-091.pdf

Bansal, R. P. and David N. Sen. (1978). Contribution to the Ecology and Seed Germination of Cucumis callosus. Folia Geobotanica \& Phytotaxonomia, Vol. 13, No. 3, pp 225-233.

Brandle, J.E. and N. Rosa. (1992). Heritability for yield, leaf-stem ratio and stevioside content estimated from a landrace cultivar of Stevia rebaudiana. Can. J. Plant Sci, 72: 1263-1266. http://dx.doi.org/10.4141/cjps92-159

Colbach, N., B. Chauvel, C. Dürr, and G. Richard. (2002). Effect of environmental conditions on Alopecurus myosuroides germination. I. Effect of temperature and light. Weed Res, Vol. 42, pp. 210-221. http://dx.doi.org/10.1046/j.0043-1737.2002.00279.x

Datta, J.K., Nag, S., Banerjee, A., Mondal, N.K. (2009). Impact of salt stress on five varieties of Wheat (Triticum aestivum L.) cultivars under laboratory condition. Journal of Applied Sciences \& Environmental Management, Vol. 13, No. 3, Sept, 2009, pp. 93-97 ISSN: 1119-8362.

David N. Sen and D.D. Chawan. (1970). Role of light and Temperature in relation to seed germination of Astercantha longifolia Nees.. Plant Systematic and Evolution, Vol. 118, No.3, 1970, pp. 226. http://dx.doi.org/10.1007/BF01377859

Forestry Department. (2011). A guide to forest seed handling. [ONLINE] available: http://www.fao.org/DOCREP/006/AD232E/AD232E08.htm (30/06/2011)

Goettemoeller, J. and A. Ching. (1999). Seed germination in Stevia rebaudiana. p. 510-511. In: J. Janick (ed.), Perspectives on new crops and new uses. ASHS Press, Alexandria, VA.

Hossain M. A., Arefin, M.K., Khan B.M. and Rahman M.A. (2005). Effects of Seed Treatments on Germination and Seedling Growth Attributes of Horitaki (Terminalia chebula Retz.) in the nursery. Research Journal of Agriculture and Biological Sciences, 1(2): 135-141, INSInet Publication.

Lewis, W. H. (1992). Early uses of Stevia rebaudiana (Asteraceae) leaves as a sweetener in Paraguay. Econ. Bot, 46: 336-337. http://dx.doi.org/10.1007/BF02866633

Lincoln Taiz and Eduardo Zeiger. (2011). A Companion to Plant Physiology in the Fifth Edition, Types of Seed Dormancy and the Roles of Environmental Factors, 690 pages., Chapter 23, Topic 23. 18. By Sinauer Associates. ISBN-10: 0878938230, ISBN-13: 978-0878938230.

Robert C. Artkins. (2010). New Diet revolution. Hea lthier-Harvest 2009.

http://healthier-harvest.com/news-articles/nutritional_information/stevia.htm

Rubio-Casal, A.E., Castillo, J. M. Luque C. J and Figueroa M. E. (2003). Influence of salinity on germination and seed viability of two primary colonizers of Mediterranean salt pans. Journal of Arid Environment, 53:

145-154. http://dx.doi.org/10.1006/jare.2002.1042

Sakaguchi, M. and T. Kan. (1992). Japanese researches on stevia rebaudiana (Bertoni and stevioside. Ci, Cult., 34: 235-248.

Shyam S. Sharma and David N. Sen. (1975). Effect of light on seed germination and seedling growth of Merremia species. Folia Geobotanica \& Phytotaxonomia, Vol. 10, No.3, pp. 265-269.

Soejarto, D.D., Compadre, C.M., Medon, P.J., Kamath, S.K., and Kinghorn, A.D. (1983). Potential sweetening agents of plant origin. II. Field search for sweet-tasting Stevia species. Econ. Bot. 37: 71-79. http://dx.doi.org/10.1007/BF02859308

Soejarto, D.D., Kinghorn, A.D., and Farnsworth, N.R. (1982). Potential sweetening agents of plant origin. III. Organoleptic evaluation of stevia leaf herbarium samples for sweetness. J. Nat. Prod, 45: 590-599. http://dx.doi.org/10.1021/np50023a013

Steel, R. G. D., and Torrie, J. H.. (2010). Principles and Procedures of Statistics, Biometrical Approach. McGraw-Hill Kogakusha, Ltd.

Strauss, S. (1995). The perfect sweetener Technol. Rev. 98: 18-20. 
Table 1. Showing the effects of red \& white lights on period of germination and number of germinated seeds along with the Control set up

\begin{tabular}{|c|c|c|c|c|c|c|c|}
\hline \multirow[t]{2}{*}{$\mathrm{S} / \mathrm{N}$} & \multirow[t]{2}{*}{$\begin{array}{l}\text { P SG } \\
\text { (days) }\end{array}$} & \multicolumn{3}{|c|}{$\begin{array}{l}\text { Number of Germinated Seeds with } \\
\text { Different Treatments. }\end{array}$} & \multicolumn{3}{|c|}{ CPG } \\
\hline & & $\begin{array}{l}\text { red light } \\
(660 \mathrm{~nm})\end{array}$ & $\begin{array}{l}\text { white light } \\
(400-700 \mathrm{~nm})\end{array}$ & $\begin{array}{l}\text { planting } \\
\text { tray with } \\
\text { peat moss } \\
\text { (control) }\end{array}$ & $\begin{array}{l}\text { red } \\
\text { light }\end{array}$ & $\begin{array}{r}\text { white } \\
\text { light }\end{array}$ & $\begin{array}{l}\text { Planting } \\
\text { tray with } \\
\text { peat moss } \\
\text { (control) }\end{array}$ \\
\hline 1. & $3<5$ & 03 & - & - & 03 & 0 & 0 \\
\hline 2. & $5<7$ & 17 & 02 & - & 20 & 02 & 0 \\
\hline 3. & $7<9$ & 07 & 25 & - & 27 & 27 & 0 \\
\hline 4. & $11<13$ & 12 & - & 10 & 39 & 27 & 10 \\
\hline 5. & $17<19$ & 02 & 04 & 04 & 41 & 31 & 14 \\
\hline
\end{tabular}

Key: PSG- period of seed germination; CGP- cumulative germination percentage

Table 2. Showing data on evaluated seed germination parameters in Stevia rebaudiana

\begin{tabular}{|l|l|l|l|l|l|l|l|}
\hline S/N & $\begin{array}{l}\text { GERMINATION } \\
\text { TREATMENTS ON } \\
\text { SEEDS. }\end{array}$ & MTG & MDG & GR & DGS & GV & FGP (\%) \\
\hline 1. & Red Light treatment. & 5.13 & 2.28 & 5.00 & 8.23 & 1.87 & 41 \\
\hline 2. & White Light treatment. & 6.88 & 1.72 & 6.45 & 7.75 & 1.33 & 31 \\
\hline 3. & $\begin{array}{l}\text { Control. (Planting tray with } \\
\text { peat moss) }\end{array}$ & $\mathbf{0 . 0 0}$ & $\mathbf{0 . 8 3}$ & $\mathbf{1 2 . 0 0}$ & 1.77 & $\mathbf{0 . 1 5}$ & 14 \\
\hline
\end{tabular}

Key: MTG-mean time germination; MDG-mean daily germination; GR-germination rate; DGS-daily germination speed; GV- germination value, and FGP-final germination percentage 
Period of germination in stevia seeds with red ligt

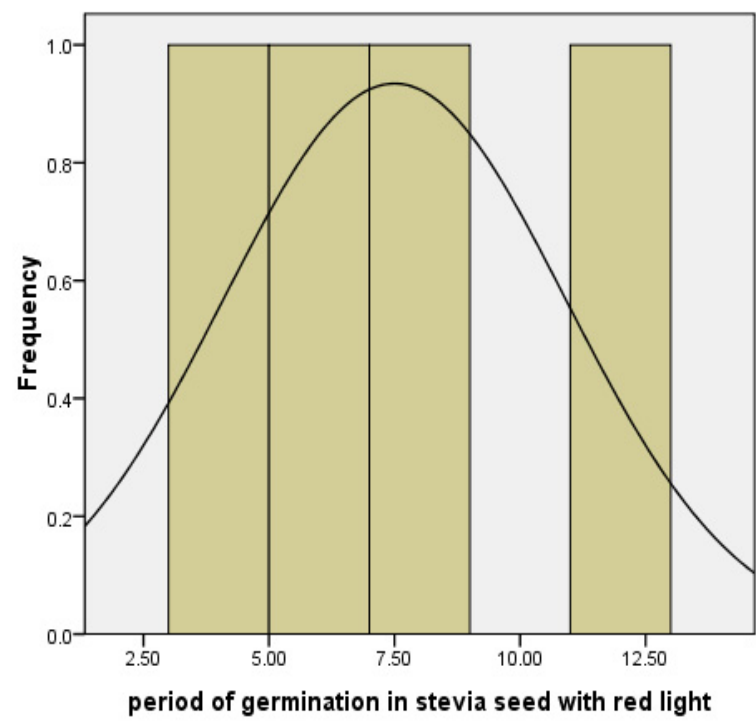

Mean $=7.50$
Std. Dev. $=3.416$
$N=4$

Figure 1a. Showing period of germination in stevia seeds treated with red light

\section{Period of germination in stevia seeds with white light}

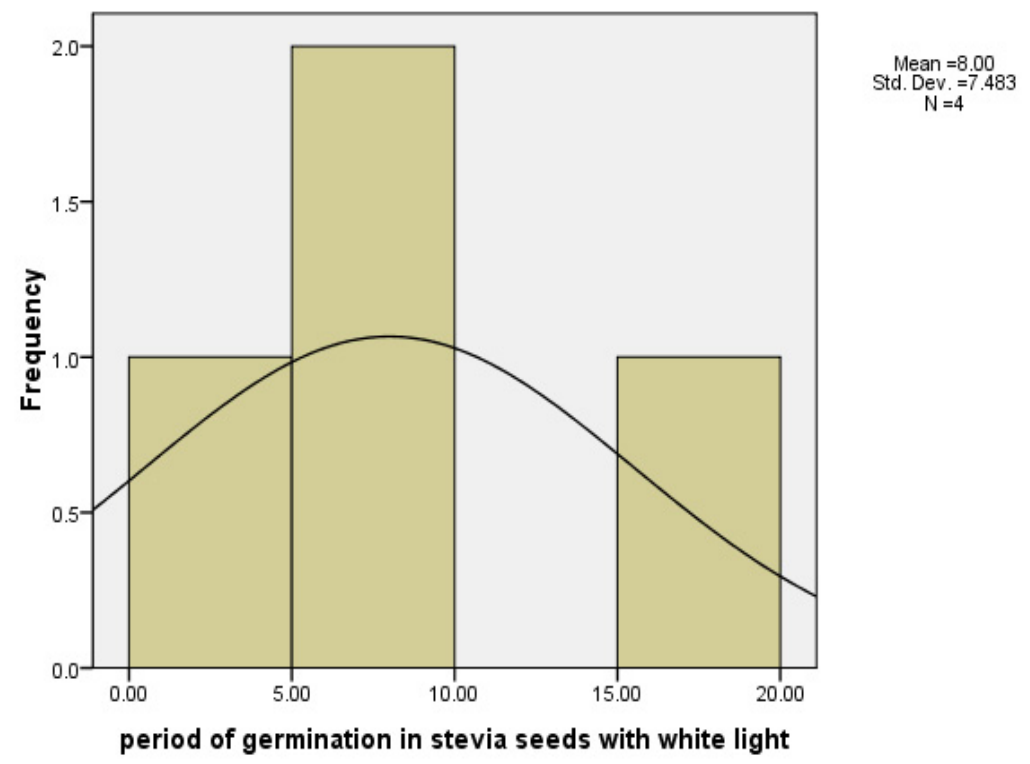

Figure $1 \mathrm{~b}$. Showing period of germination in stevia seeds treated with white light 


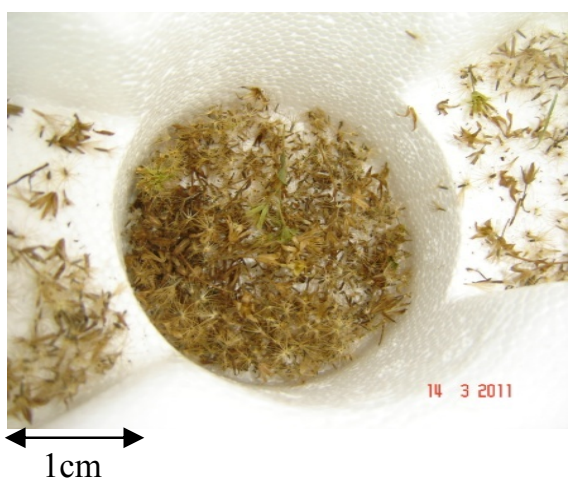

Figure 2a

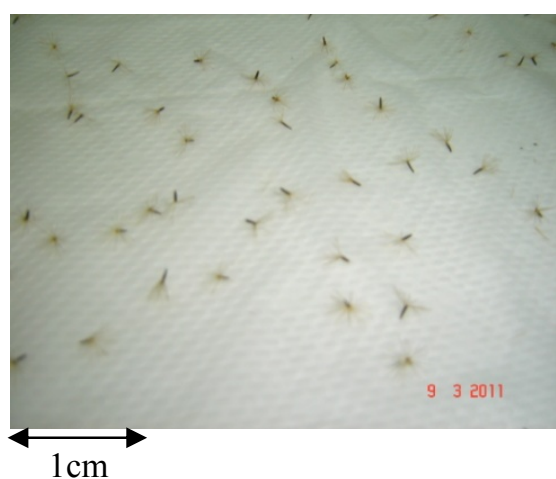

Figure $2 b$

Figure 2a. Showing collected Stevia seeds in polystyrene; while figure 2b. Showing spread of Stevia seeds on paper towel

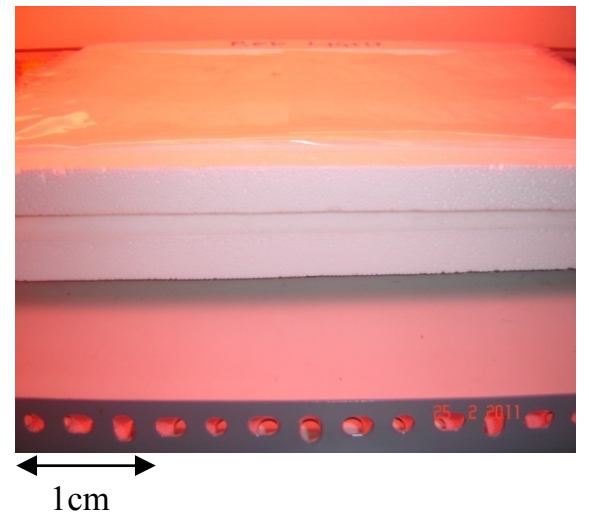

Figure 3a

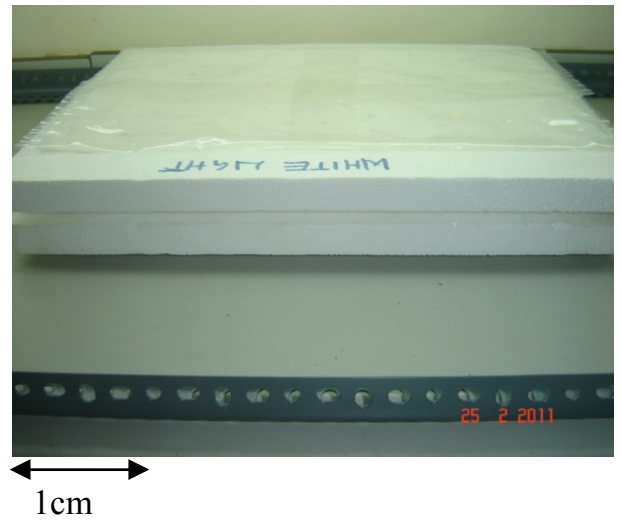

Figure 3b

Figure 3a. Showing red light $(660 \mathrm{~nm})$ chamber containing seeds of Stevia in paper towel; while figure 3b. Showing white light (400-700 nm) chamber also containing seeds of Stevia in paper towel

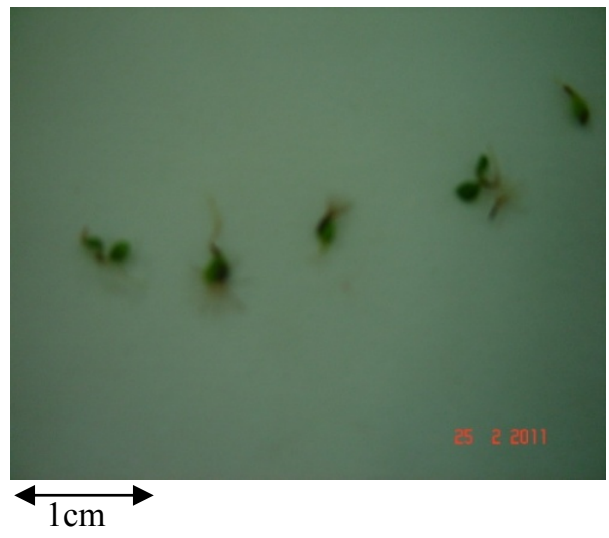

Figure 4a

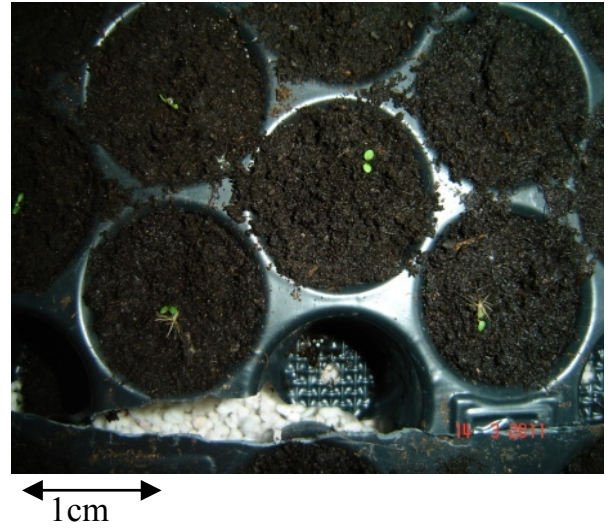

Figure $4 \mathrm{~b}$

Figure 4a. Showing some germinated seeds from light chambers; while figure $4 \mathrm{~b}$. Showing planting tray filled with peat moss containing germinated seeds 


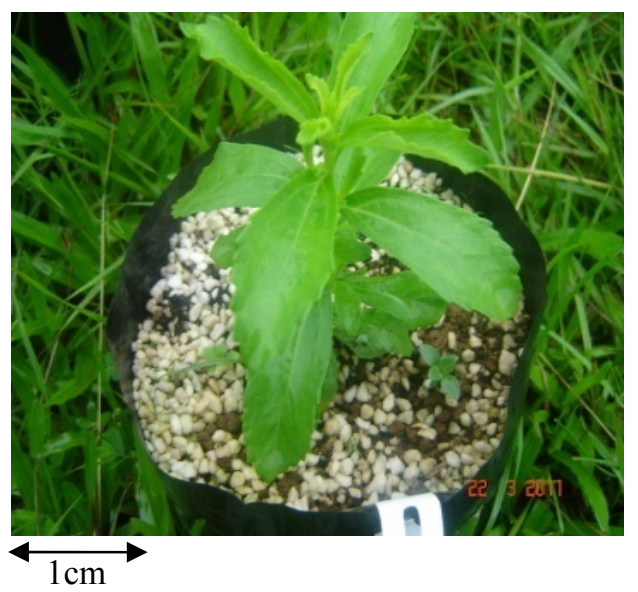

Figure 5a

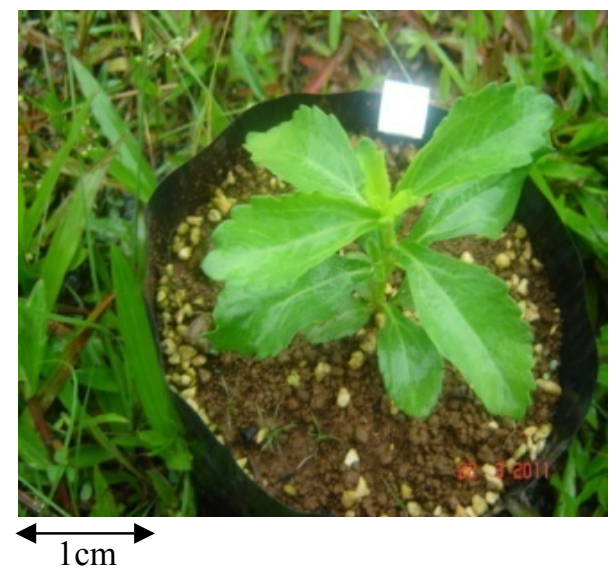

Figure $5 \mathrm{~b}$

Figure 5a \& 5b. Showing growing seedling of Stevia plants in polythene bags placed on the field 